\title{
ANTENATAL ANXIETY AND DEPRESSION AMONG PREGNANT WOMEN ATTENDING TERTIARY CARE HOSPITAL, MARDAN, PAKISTAN
}

\section{Ejaz Gul', Pirzada Muhammad Muneeb ${ }^{1 \otimes}$, Mukhtiar UI Haq Azeemi', Muhammad Abbas Khan', Sumaira Shah'}

\begin{abstract}
OBJECTIVE: To determine the frequency of anxiety and depression among pregnant women attending antenatal out-patient department of a public hospital based in Mardan, Pakistan.

METHODS: This cross-sectional study was conducted at Bacha Khan Teaching Hospital and Mardan Medical Complex, Mardan from October 2017 to April 2018. The study included 212 pregnant women during their routine antenatal checkup with the gynecologist during all three trimesters of pregnancy. Convenience sampling method was used and structured interview was conducted to obtain demographic information. Hamilton Depression rating scale and Hamilton anxiety rating scale (HAM-A) was used to assess symptoms of depression and anxiety respectively.

RESULTS: Out of 212 pregnant women, most were uneducated $(n=96$, $45.3 \%)$, housewives $(n=182,85.8 \%)$, from rural area $(n=1 \mid 14,53.8 \%)$, in $3 r d$ trimester of pregnancy $(n=132,62.3 \%)$, having planned pregnancy $(n=174$, $82.1 \%)$ and desirous of male child $(n=94,44.3 \%)$. Mean age of women was $25.55 \pm 5.52$ years. Mild depression was present among $68(32.1 \%)$, moderate depression in $64(30.2 \%)$, severe depression in 24 (11.3\%) and very severe depression in $20(9.4 \%)$ women. According to HAM-A scores, $70(33 \%)$ of the participants scored in normal range, $44(20.8 \%)$ lied in mild anxiety range, 62 $(29.2 \%)$ lied in moderate anxiety while $36(17 \%)$ lied in severe anxiety range. Levels of depression and anxiety were highest among women of third trimester.
\end{abstract}

CONCLUSION: Frequency of anxiety and depression is very high among pregnant women in our study population. Majority were uneducated, housewives, having rural origin, in 3rd trimester and desirous of male child.

KEY WORDS: Pregnancy (MeSH); Anxiety (MeSH); Depression (MeSH); Hamilton depression rating scale (Non-MeSH); Hamilton anxiety rating scale (Non-MeSH).

THIS ARTICLE MAY BE CITED AS: Gul E, Muneeb MP, Azeemi MUH, Khan MA, Shah S. Antenatal anxiety and depression among pregnant women attending tertiary care hospital, Mardan, Pakistan. Khyber Med Univ J 2019;। I(3):I60-4. DOI: 10.35845/kmuj.2019.18607

\section{INTRODUCTION}

$R^{\mathrm{e}}$ eproductive years in a women's life s the highest risk period for developing mental health related problems.' Excessive chronic life stressors may make women unable to cope with the additional demands of gestation period.' Pregnancy along with predisposition to stressful life conditions as poverty or already with dependent children generate negative feelings in many women. ${ }^{2}$ There is also incidence of disturbed relationships between couples because of increase in domestic violence during pregnancy. ${ }^{3}$

Pregnancy accompanies anticipated

I. Department of Psychiatry, Mardan Medical Complex, Bacha Khan Medical College, Mardan, Pakistan.

Email凶 :pir_muneeb@hotmail.com Contact\#: +92-334-9011907

Date Submitted:

Date Revised:

Date Accepted:

uncertainty associated with it, due to which pregnancy may give rise to many apprehensions even in healthy women. Pregnancy anxiety may also lead to depression during the pregnancy and post-natal period. Women belonging to low and middle-income countries are at higher risk of developing depression during reproductive years. ${ }^{4}$ Research suggests that anxiety and depression during the antenatal period have negative outcomes for pregnant women's health and can lead to adverse child development. It may also lead to complications during pregnancy including prolonged labor, premature birth and low birth weight. ${ }^{5,6}$ Range of fetal and obstetric problems during the antenatal period are associated to depression according to evidence from low and middle-income countries. ${ }^{6,7}$

Some of the risk factors that may held women at an increased risk for antenatal depression includes past history of depressive illness, financial problems, illiteracy, unemployment, substance abuse, poor social support and domestic violence.

A Pakistani based study exploring associated factors of depression during pregnancy has reported that increasing age, low educational attainment, abuse from husband, neglect, putting restrictions on wife, interference by in laws and heavy household works were significant predictors of depression during pregnancy.' Another study identified local country-specific stressors associated with anxiety and depression in Pakistani antenatal women. ${ }^{10}$

Depressive symptoms in pregnant women, despite of its consequences on the mother and the child are not given quite much attention and in majority of the cases are left untreated." Pregnancy and outcomes may be improved if early 
TABLE I: DEMOGRAPHIC CHARACTERISTICS OF PARTICIPANTS

\begin{tabular}{|c|c|c|c|}
\hline \multicolumn{2}{|c|}{ Demographic Characteristics } & $\begin{array}{c}\text { Frequency } \\
(n=2 \mid 2)\end{array}$ & Percentage \\
\hline \multirow{6}{*}{ Education } & Uneducated & 96 & 45.3 \\
\hline & Primary & 36 & 17 \\
\hline & Matric & 30 & 14.2 \\
\hline & Intermediate & 12 & 5.7 \\
\hline & Bachelors & 18 & 8.5 \\
\hline & Masters & 20 & 9.4 \\
\hline \multirow{2}{*}{ Profession } & Housewife & 182 & 85.8 \\
\hline & Employed & 30 & 14.2 \\
\hline \multirow{3}{*}{ Trimester of Pregnancy } & Ist Trimester & 28 & 13.2 \\
\hline & 2nd Trimester & 52 & 24.5 \\
\hline & 3rd Trimester & 132 & 62.3 \\
\hline \multirow{2}{*}{ Pregnancy planning } & Planned & 174 & 82.1 \\
\hline & Unplanned & 38 & 17.9 \\
\hline \multirow{3}{*}{ Desired Gender of Child } & Male & 94 & 44.3 \\
\hline & Female & 48 & 22.6 \\
\hline & Not specified & 70 & 33 \\
\hline \multirow{2}{*}{ Address } & Urban & 98 & 46.2 \\
\hline & Rural & $\mathrm{II} 4$ & 53.8 \\
\hline \multirow{5}{*}{ Depression } & Normal & 36 & 17 \\
\hline & Mild Depression & 68 & 32.1 \\
\hline & Moderate Depression & 64 & 30.2 \\
\hline & Severe Depression & 24 & 11.3 \\
\hline & Very severe Depression & 20 & 9.4 \\
\hline \multirow{4}{*}{ Anxiety } & Normal & 70 & 33 \\
\hline & Mild Anxiety & 44 & 20.8 \\
\hline & Moderate Anxiety & 62 & 29.2 \\
\hline & Severe Anxiety & 36 & 17 \\
\hline
\end{tabular}

identification and treatment of depression is carried out by health care practitioners.

The aim of the current study was to estimate the frequency of depression and anxiety among pregnant women during their first, second and third trimesters of pregnancy attending antenatal out-patient department of a public hospital based in Mardan.

\section{METHODS}

Pregnant women of first, second and third trimesters waiting for routine checkup and consultation with the gynecologist in a tertiary care hospital at Mardan were invited for the study. Those willing to participate in the study were asked to fill and sign the informed consent form. Afterwards, questionnaire regarding demographic information was filled from the participants.
Hamilton Depression Rating Scale, was used to assess severity of symptoms of depression. HAM-D is clinician rating scale widely used to assess severity of symptoms of depression in clinical trials. HAM-D consists of 21 items and measures severity of depression among those diagnosed as depressed.

Hamilton Anxiety Rating Scale, was used to assess symptoms of anxiety. HAM-A is a well known and widely used clinician rating screening tool for anxiety.

Structured questions were asked to obtain information regarding educational level, trimester of pregnancy, pregnancy planning, number of miscarriages and still births, history of psychological disorders, family history of psychological disorders (depression, anxiety), medical problems (hypertension, diabetes) and economic status. Hamilton depression rating scale $(H A M-D)^{12}$ and Hamilton anxiety rating scale (HAM-A) ${ }^{13}$ were used to assess depression and anxiety. During assessment, any women found having any psychiatric disorder or suicide intent were referred to psychiatry unit for management.

Ethical approval for the study was obtained from the Research Committee and Ethics Review Board of Bacha Khan Medical College and Mardan Medical Complex. The data was collected from I8-October-2017 to April 2018.

For this study a total of 250 women waiting for their routine checkup and consultation with gynecologist were approached for gathering data. Among the total sample of 250,38 of the females did not agreed to participate in the study. The final sample was 212 . The sample ranged in age from 16-40 years.

Pregnant women to be included in this study were required to be of 16 years of age. Women with severe medical problems as diabetes, hypertension, HIV related infections or severe pregnancy related complications were not included in the study and were referred to specialists for treatment.

The results were analyzed using statistical package for social sciences (IBM SPSS, Version 22, Armonk, New York). For parametric data, an independent sample t-test was used to compare the mean difference between groups.

\section{RESULTS}

Mean age of the study samples was $25.55 \pm 5.518$ years (age range was 16 40 years). Out of 212 pregnant women, most were uneducated $(96,45.3 \%)$, housewives (I82, 85.8\%), from rural area $(114,53.8 \%)$, in 3rd trimester of pregnancy $(132,62.3)$, having planned pregnancy $(174,82.1 \%)$ and desirous of male child $(94,44.3 \%)$. Out of the 212 pregnant women, mild depression was found to be present among 68 (32.1\%), moderate depression was found among $64(30.2 \%)$, severe depression was found among 24 (II.3\%) and very severe depression among 20 (9.4\%). According to HAM-A scores, 70 (33\%) of the participants scored in the normal range, $44(20.8 \%)$ lied in the mild anxiety range, $62(29.2 \%)$ lied in the 
moderate anxiety while 36 (17\%) lied in the severe anxiety range (Table I). Levels of depression and anxiety were highest among women of third trimester (Table II \& III).

\section{DISCUSSION}

Numerous studies have demonstrated the fact that antenatal depression is to a larger extent as common as postnatal depression and meta-analyses have shown that antenatal depression highly influences the occurrence of postnatal depression. ${ }^{14}$ Varying rates of the prevalence of antenatal depression are noted from the findings of different studies. According to findings from prevalence rates of depression from developing countries, the average rate of depression was $20 \%$ ranging from 6.4 to $30 \%$. In developed countries, the average rate of depression was 15\% ranging from 8 .I to $56 \% .8$ According to the results of the current study the rates of depression and anxiety are quite high among the antenatal population. According to HAM-D scores obtained, 108 (50.9\%) pregnant women lied in the range of moderate to very severe depression (moderate depression $30.2 \%$, severe depression $11.3 \%$, and very severe depression $9.4 \%$ ). Significant relationship between lower income status and antenatal anxiety and depression has been observed from a study of an urban community in Pakistan. ${ }^{15}$

A Pakistani study exploring depression among pregnant women found almost similar prevalence rates of $48.4 \%$ of depression, ${ }^{16}$ which in our study is $51 \%$. Another study showed that about twothird of antenatal women attending antenatal clinic were anxious and depressed. ${ }^{10}$ Study from antenatal clinics of Karachi, Pakistan exploring depression among pregnant women also found prevalence rates of $45.3 \%$ of depression. ${ }^{17}$ Yet another study from Lahore found $75.1 \%$ of women scoring above the cut-off score of 10 on Edinburgh Postnatal Depression Scale (EPDS). ${ }^{18}$ A Brazilian study found $23.6 \%$ prevalence rate of depression among women in their $2^{\text {nd }}$ and $3^{\text {rd }}$ trimesters. ${ }^{19}$ Another recent study found prevalence rate of $16 \%$ among Brazilian pregnant women. In this study the factors strongly associated to higher depression scores were high parity and maternal education. ${ }^{20}$ A study from Nigeria found significant relationship between antenatal depression and lack of formal education, young maternal age and large family size. ${ }^{21}$

Depression in the second and third trimesters is strongly correlated to postpartum depression and may lead to worst child outcomes. ${ }^{22}$ The findings of a meta-analysis comparing rates of depression between pregnant women and those of general female population. It was noted that rates of depression during the $I^{\text {st }}$ trimester were equivalent to rates observed in the general female population, while rates during second and third trimester were double of those from general population. ${ }^{4}$ In our study levels of moderate to severe depression was noted among 35\% female who were in their third trimester of pregnancy. The same pattern of increased vulnerability to depression during the third trimester has also been noted in studies from Asia and Africa which indicates that prevalence rates would be high in low income countries too where prevalence rates range between $35 \%$ and $50 \%$ in the third trimester. ${ }^{23-25}$ Therefore, depression during the antenatal period should be ruled out during routine visits to antenatal clinics in tertiary care hospitals.

Anxiety was also quite high among the pregnant women but these levels of anxiety were relatively low in comparison to depression. According to HAM-A scores, 98 (46.2\%) of the pregnant women lied in the moderate to severe anxiety range. A study from Bangladesh found prevalence rates of $29.4 \%$ of pregnancy related anxiety among the pregnant women. ${ }^{26}$ Among the limited researches on the given topic in Pakistan, a study of pregnant women of tertiary care hospital found anxiety among $53 \%$ of the study population, while both anxiety and depression were found among almost $70 \%$ of the women. ${ }^{27}$ One study from antenatal clinic of a teaching hospital of Lahore assessed pregnant women for anxiety and depression, the findings reported that $34.5 \%$ of women were suffering anxiety while $25 \%$ suffering from depression. ${ }^{28}$ Another study from Karachi has reported almost similar rates of anxiety and depression among the pregnant women. ${ }^{29}$ According to a study from Oman, exploring pregnancy specific anxiety, highest levels of anxiety were noted during the third trimester. Among the pregnant women, $29 \%$ had severe anxiety, while $71 \%$ had moderate anxiety during their third trimester. $^{30}$

\section{CONCLUSION}

Frequency of anxiety and depression is very high among pregnant women in our study population. Most were uneducated, housewives, having rural origin and desirous of male child.

TABLE II: FREQUENCIES OF DEPRESSION DURING THE THREE TRIMESTERS

\begin{tabular}{|c|c|c|c|c|c|c|c|}
\hline & \multicolumn{5}{|c|}{ Depression Categories } & \multirow[b]{2}{*}{ Total } \\
\hline & & Normal & \begin{tabular}{c|} 
Mild \\
Depression
\end{tabular} & $\begin{array}{l}\text { Moderate } \\
\text { Depression }\end{array}$ & $\begin{array}{c}\text { Severe } \\
\text { Depression }\end{array}$ & $\begin{array}{l}\text { Very Severe } \\
\text { Depression }\end{array}$ & \\
\hline \multirow{3}{*}{$\begin{array}{l}\text { Trimester } \\
\text { of } \\
\text { Pregnancy }\end{array}$} & $1^{\text {st }}$ & $4(14.3 \%)$ & $16(57 \%)$ & $4(14.3 \%)$ & 00 & $4(14.3 \%)$ & 28 \\
\hline & $2^{\text {nd }}$ & $16(30.7 \%)$ & $12(23 \%)$ & $10(19.2 \%)$ & $6(11.5 \%)$ & $8(I 5.3 \%)$ & 52 \\
\hline & $3^{\text {rd }}$ & $16(12.1 \%)$ & $40(30 \%)$ & $50(37.9 \%)$ & $18(13.6 \%)$ & $8(6 \%)$ & 132 \\
\hline \multicolumn{2}{|c|}{ Total } & $36(17 \%)$ & $68(32.1 \%)$ & 64 (30.2\%) & 24 (II.3\%) & 20 (9.4\%) & 212 \\
\hline
\end{tabular}

TABLE III: FREQUENCIES OF ANXIETY DURING ANTENATAL PERIOD

\begin{tabular}{|c|c|c|c|c|c|c|}
\hline & \multicolumn{4}{|c|}{ Anxiety Categories } & \multirow{2}{*}{ Total } \\
\hline & & Normal & Mild Anxiety & Moderate Anxiety & Severe Anxiety & \\
\hline \multirow{3}{*}{$\begin{array}{l}\text { Trimester } \\
\text { of } \\
\text { Pregnancy }\end{array}$} & $\mathrm{I}^{\mathrm{st}}$ & $18(64.3 \%)$ & $2(7 \%)$ & $6(21.4 \%)$ & $2(7 \%)$ & 28 \\
\hline & $2^{\text {nd }}$ & $20(38.6 \%)$ & $10(19.2 \%)$ & $10(19.2 \%)$ & $12(23 \%)$ & 52 \\
\hline & $3^{\text {rd }}$ & $32(24.2 \%)$ & $32(24.2 \%)$ & $46(35 \%)$ & $22(16.6 \%)$ & 132 \\
\hline \multicolumn{2}{|c|}{ Total } & $70(33 \%)$ & $44(20.8 \%)$ & $62(29.2 \%)$ & 36 (17\%) & 212 \\
\hline
\end{tabular}


Symptoms of anxiety and depression are common among pregnant women especially in $3^{\text {rd }}$ trimester.

\section{LIMITATIONS}

Data was collected from women during their routine visits to antenatal clinics. Large number of women were approached for data collection but many of those refused because they had to perform lab tests recommended by gynecologist. Mother's health has significant impact on child and home environment. It is recommended for future studies to conduct large scale studies so that strategies should be planned for treatment and prevention of anxiety and depression. Interventions should be carried out by health care policy makers to tackle this issue and steps should be taken for its prevention.

\section{REFERENCES}

I. Patel V, Araya R, De Lima M, Ludermir A, Todd C. Women, poverty and common mental disorders in four restructuring societies. Soc Sci Med 1999 Dec ;49(II):|46I-7I. DOI: 10.1016/s0277-9536(99)00208-7.

2. Brancaglion MYM, RückIS, Couto TC, Viana LE, Nicolato R, Filho HCdS. How Gestational Depression Impacts on Quality of Life. J Depress Anxiety 2016;5(2):1000225. DOI: 10.4|72/2|67-1044.1000225.

3. National Institute for Health and Care Excellenece (NICE) Clinical Guideline, Depression in Adults: Recognition and Management. 2009 October (Last updated April 2018). [Cited on: August 28, 2018]. Available from URL: https://www.nice.org.uk/ guidance/cg90.

4. Bennett HA, Einarson A, Taddio A, Koren G, Einarson TR. Prevalence of depression during pregnancy: systematic review. Obstet Gynecol 2004 Apr I;103(4):698-709. DOI: I0.1097/0I.AOG.0000II6689.7539 $6.5 f$.

5. Rauchfuss M, Maier B. Biopsychosocial predictors of preterm delivery. J Perinat Med 2011 Sep;39(5):5 I 5-2।. DOI: 10.1515/JPM.2011.067.

6. Alder J, Fink N, Bitzer J, Hösli I, Holzgreve W. Depression and anxiety during pregnancy: a risk factor for obstetric, fetal and neonatal outcome? A critical review of the literature. J Matern Fetal Neonatal Med 2007 Jan I;20(3): 189-209. DOI: I0.1080/I476705070I 209560.

7. World Health Organization (WHO) and United Nations Population Fund (UNPF). Mental health aspects of women's reproductive health: a global review of the literature. Geneva: World Health Organization 2009. [Cited on: August 28, 20I8]. Available from URL: https://apps. who.int/iris/handle/ I0665/43846

8. Pereira PK, Lovisi GM. Prevalence of gestational depression and associated factors. Arch Clin Psychiatry (São Paulo). 2008;35(4): I44-53. DOI: | $0.1590 /$ SOIOI-60832008000 400004.

9. Kazi A, Fatmi Z, Hatcher J, Kadir MM, Niaz U, Wasserman GA. Social environment and depression among pregnant women in urban areas of Pakistan: importance of social relations. Soc Sci Med 2006 Sep I;63(6): |466-76. DOI: $10.1016 / \mathrm{j}$. socscimed.2006.05.019.

10. Gul F, Sherin A, Jabeen M, Khan SA. Association of stress with anxiety and depression during pregnancy. J Pak Med Assoc 2017 Dec;67( I 2): 1803-8.

II. Vesga-Lopez O, Blanco C, Keyes K, Olfson M, Grant BF, Hasin DS. Psychiatric disorders in pregnant and postpartum women in the United States. Arch Gen Psychiatry 2008 Jul 7;65(7):805-I5. DOI: 10.1001/ archpsyc.65.7.805.

12. Hedlund JL, Vieweg BW. The Hamilton rating scale for depression: a comprehensive review. J Operational Psychiatry 1979;10(2): 149-65.

13. Hamilton MC. Hamilton anxiety scale (HAMA). In: Sourcebook of Adult Assessment: Applied Clinical Psychology. Schutte NS, Malouff JM (eds). Plenum Press, New York 1959. pl54-7.

14. Lancaster CA, Gold KJ, Flynn HA, Yoo H, Marcus SM, Davis MM. Risk factors for depressive symptoms during pregnancy: a systematic review. Am J Obstet Gynecol 2010 Jan;202(I):5I4. DOI: 10.1016/j.ajog.2009.09.007.

15. Karmaliani R, Asad N, Bann CM, Moss
$\mathrm{N}$, Mcclure EM, Pasha $\mathrm{O}$, et al. Prevalence of anxiety, depression and associated factors among pregnant women of Hyderabad, Pakistan. Int J Soc Psychiatry 2009 Sep;55(5):4I424. DOI: $10.1 \mid 77 / 00207640080$ 94645 .

16. Shah SM, Bowen A, Afridi I, Nowshad G, Muhajarine N. Prevalence of antenatal depression: comparison between Pakistani and Canadian women. J Pak Med Assoc 20II Mar I;6I(3):242-6.

17. Jafri SAM, Ali M, Ali R, Shaikh S, Abid M, Aamir IS. Prevalence of Depression among Pregnant Women Attending Antenatal Clinics in Pakistan. Acta Psychopathol 2017;3:54. DOI: 10.4172/2469. 6676.100126 .

18. Humayun A, Haider II, Imran N, Iqbal $\mathrm{H}$, Humayun N. Antenatal depression and its predictors in Lahore, Pakistan. East Mediterr Health J 2013 Apr;19(4):327-32.

19. Castro e Couto T, Cardoso MN, Brancaglion MM, Faria GC, Garcia FD, Nicolato $R$, et al. Antenatal depression: Prevalence and risk factor patterns across the gestational period. J Affect Disord $2016 \mathrm{Mar}$ I;192:70-5. DOI: 10.1016/j.jad. 2015.12.017.

20. Coll CD, da Silveira MF, Bassani DG, Netsi E, Wehrmeister FC, Barros FC, et al. Antenatal depressive symptoms among pregnant women: Evidence from a Southern Brazilian populationbased cohort study. J Affec Disord 2017 Feb;209:I40-6. DOI: 10.1016/j.jad.2016.11.031.

2I. Thompson O, Ajayi I. Prevalence of antenatal depression and associated risk factors among pregnant women attending antenatal clinics in Abeokuta North Local Government Area, Nigeria. Depress Res Treat 20।6;2016:45।8979. DOI: $10.1|55 / 2016 / 45| 8979$.

22. Park JH, Karmaus W, Zhang $\mathrm{H}$. Prevalence of and risk factors for depressive symptoms in Korean women throughout pregnancy and in postpartum period._AsianNurs Res (KoreanSoc Nurs Sci). 2015 Sep;9(3):219-25. DOI: 10.1016/j.anr. 2015.03.004.

23. Abiodun OA. Postnatal depression in 
primary care populations in Nigeria. Gen Hosp Psychiatry 2006 MarApr;28(2):133-6. DOI: 10.1016/j. genhosppsych.2005.II.002.

24. Esimai OA, Fatoye FO, Quiah AG, Vidal OE, Momoh RM. Antepartum anxiety and depressive symptoms: A study of Nigerian women during the three trimesters of pregnancy. J Obstet Gynaecol 2008 Jan I;28(2):202-3. DOI: 10.1080/ 01443610801912352.

25. Lau Y, Wong DF, Chan KS. The utility of screening for perinatal depression in the second trimester among Chinese: a three-wave prospective longitudinal study. Arch Womens
Ment Health 2010 Apr; I3(2): 153-64. DOI: I0. 1007/s00737-009-0|34-x.

26. Nasreen HE, Kabir ZN, Forsell $Y$, Edhborg M. Prevalence and associated factors of depressive and anxiety symptoms during pregnancy: a population based study in rural Bangladesh. BMC Womens Health 201 I Dec;II(I):22. DOI: 10.1I86/ |472-6874-|| |-22.

27. Ali NS, Azam IS, Ali BS, Tabbusum G, Moin SS. Frequency and associated factors for anxiety and depression in pregnant women: a hospital-based cross-sectional study. Sci World 20।2;20| 2:653098. DOI: 10.1100/ $2012 / 653098$.
28. Niaz S, Izhar N, Bhatti MR. Anxiety and depression in pregnant women presenting in the OPD of a teaching hospital. Pak J Med Sci 2004;20(2): II7-9.

29. Hamirani MM, Sultana A, Ibrahim Z, Iqbal $H$, Sultana $S$. Frequency of prenatal depression in second and third trimesters of pregnancy in Karachi: a hospital based study. J Liaquat Univ Med Health Sci 2006;5(3): 106-9.

30. Madhavanprabhakaran GK, D'Souza MS, Nairy KS. Prevalence of pregnancy anxiety and associated factors. Int J Africa Nurs Sci 20 I 5;3: I 7. DOI: I0.10I6/j.ijans.20I5.06.002.

\section{AUTHORS' CONTRIBUTIONS}

Following authors have made substantial contributions to the manuscript as under:

EG \& MUHA: Conception and design, acquisition of data, drafting the manuscript, final approval of the version to be published

PMM, MAK \& SS: Acquisition, analysis and interpretation of data, drafting the manuscript, critical review, final approval of the version to be published

Authors agree to be accountable for all aspects of the work in ensuring that questions related to the accuracy or integrity of any part of the work are appropriately investigated and resolved.

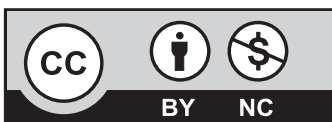

This is an Open Access article distributed under the terms of the Creative Commons Attribution-Non Commercial 2.0 Generic License.

KMUJ web address: www.kmuj.kmu.edu.pk

Email address: kmuj@kmu.edu.pk 